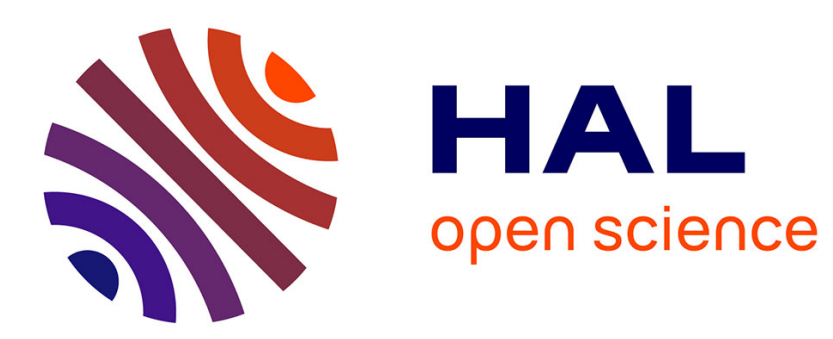

\title{
SERIES ANALYSIS OF STERIC INTERACTION MODELS IN SMECTIC B PLANE
}

\author{
G. Coulon, Michel Descamps
}

\section{To cite this version:}

G. Coulon, Michel Descamps. SERIES ANALYSIS OF STERIC INTERACTION MODELS

IN SMECTIC B PLANE. Journal de Physique Colloques, 1979, 40 (C3), pp.C3-132-C3-135. 10.1051/jphyscol:1979327 . jpa-00218723

\section{HAL Id: jpa-00218723 \\ https://hal.science/jpa-00218723}

Submitted on 1 Jan 1979

HAL is a multi-disciplinary open access archive for the deposit and dissemination of scientific research documents, whether they are published or not. The documents may come from teaching and research institutions in France or abroad, or from public or private research centers.
L'archive ouverte pluridisciplinaire HAL, est destinée au dépôt et à la diffusion de documents scientifiques de niveau recherche, publiés ou non, émanant des établissements d'enseignement et de recherche français ou étrangers, des laboratoires publics ou privés. 


\title{
SERIES ANALYSIS OF STERIC INTERACTION MODELS IN SMECTIC B PLANE
}

\author{
G. COULON and M. DESCAMPS \\ Equipe de Dynamique des Cristaux Moléculaires, \\ Université de Lille I, B.P. 36, 59650 Villeneuve d'Ascq, France
}

\begin{abstract}
Résumé. - Nous proposons, ici, une nouvelle méthode de calcul de la diffusion $\mathrm{X}$ en dehors des taches de Bragg qui consiste à écrire cette dernière sous forme d'un développement en série de graphes en chaque vecteur $\mathbf{Q}$ du réseau réciproque. Cette méthode nous permet de tester les différents modèles de corrélations induites par l'encombrement stérique pour chaque type de conformation moléculaire envisageable dans une mésophase smectique B. Nous montrons qu'une assemblée composée uniquement de molécules gauches ne peut pas conduire à la diffusion $\mathrm{X}$ observée expérimentalement, alors qu'une assemblée de molécules trans avec encombrement stérique relâché le peut.

Abstract. - We propose, here, a new method of calculating the out-of-Bragg X-ray scattering which consists in writing directly the latter as a graphical series expansion in each vector $\mathbf{Q}$ of the reciprocal lattice. This method allows us to test the different correlations models involved by steric hindrance according to all the possible molecular conformations in a smectic B mesophase. We show that an assembly of only gauche molecules cannot lead to the experimentally observed X-ray scattering, whereas an assembly of trans ones, with relaxed steric hindrance, can do $1 \mathrm{t}$.
\end{abstract}

1. Introduction. - In all the smectic $\mathbf{B}$ phases, tilted or not, the molecules are, in each layer, arranged in a two dimensional hexagonal (or approximatively hexagonal) array. Several experimental studies [1, 2] have proved that the molecules rotate around their long axis, a result which is consistent with the $\mathrm{X}$-ray diffraction experiment [3]. Besides, by means of X-ray scattering experiment $[4,5]$ Levelut et al. have shown that the molecules rotate probably by $\pi / 3$ orientational jumps and that the phenyl rings arrange themselves locally in a herring-bone type packing. Then, their conclusion was that the molecular rotational motions are geared. Furthermore, if we compare the size of the phenyl rings $(\simeq 6.4 \AA)$ and the lattice parameter $(\simeq 5.18 \AA)$ it is clear that steric hindrance makes some simultaneous configurations of neighbouring molecules impossible.

In a previous paper [6], we considered, from a theoretical point of view, to what extent steric hindrance between phenyl rings could generate the observed local herring-bone order referred above. A simple model, assuming that the molecules can take three orientations, with strict steric effect on both sides of a phenyl ring, made it possible to account for the observed X-ray scattering patterns; nevertheless, we had remarked that the correlation functions used for the evaluation of the X-ray scattering were rather slowly convergent.

But, very recently, Charvolin and Deloche [7], have suggested the occurrence of intramolecular rotations around the para axis of the aromatic core; this implies that the phenyl rings of a molecule rotate independently and all the molecular conformations are possible in the range from the planar trans shape to the planar gauche one shown figure 1 . Likewise, Doucet [8], by comparing the distances between molecular layers in the crystalline phase and the smectic B one in TBBA as well, concludes

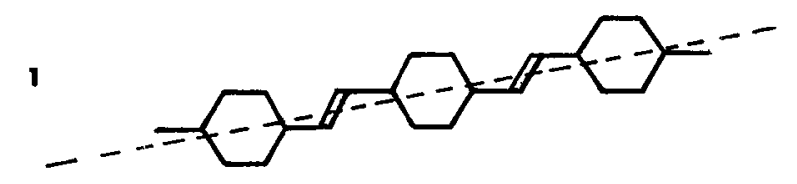

2

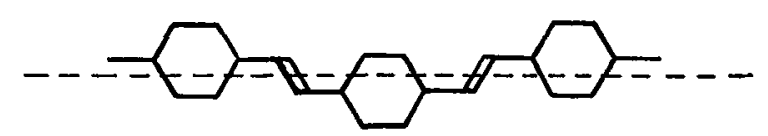

FrG. 1. - Two planar configurations of TBBA : trans (1) and gauche (2). 
that there must be a certain percentage of trans molecules in this phase, while there are only gauche molecules in the crystalline phase.

It appears that the different possible conformations do not involve, from a steric point of view, interactions of a same type between neighbouring molecules. Indeed, in a trans molecule, the molecular axis coincides with the para axis of its phenyl rings and so the steric effect occurs on both sides of a phenyl ring (Fig. 2). On the other hand, in a gauche molecule, the phenyl rings are no longer symmetrical with respect to the molecular axis; so, because of the large thermal vibrations of the molecule, we can see on figure 2 that steric effect occurs only on one side of a phenyl ring. The correlations involved in each case must lead to different X-ray scattering patterns. Such is our purpose.

So, we propose a new method of calculating the out-of-Bragg X-ray diffuse scattering [9] which consists in writing directly the latter as a graphical series expansion in each vector $\mathbf{Q}$ of the reciprocal lattice. This method is well suited when all or nothing interactions are suspected and its formalism allows to test different interaction models easily because, contrary to our first calculation [6], this technique avoids the explicit use of the correlation functions. Besides, contrary to the classical approximative methods all the calculated orders are exact; and this makes us able to analyse very accurately the series convergence in each reciprocal point $\mathbf{Q}$.

According to that method we are going to test two interaction models which correspond to the two
1
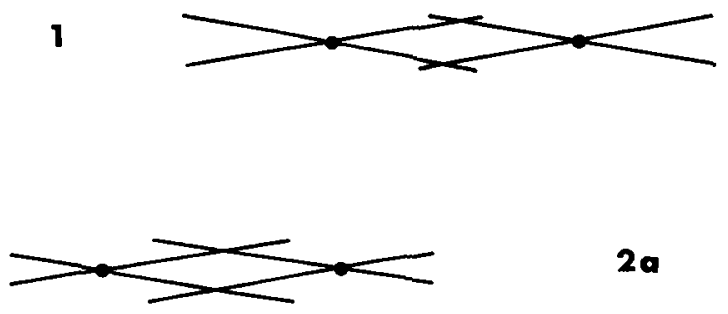

2a

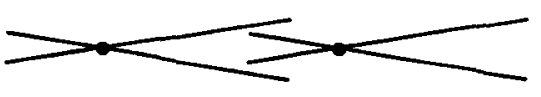

Fig. 2. - Steric effect in the case of a trans molecule (1) and a gauche one $(2 a)$. The configuration $(2 b)$ of the gauche molecule is possible.

extreme cases sterically : - trans molecules assembly ( 3 orientations model) - gauche molecules assembly (6 orientations model) (Fig. 3); furthermore, owing to the flexibility of this method, we here take into account the relaxation of the steric hindrance due in part to the thermal motions.
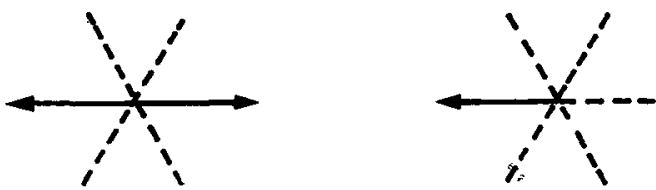

FIG. 3. - Three (1) and six (2) orientations models.

2. Theory. - Let us describe the method for the 3 orientations model in the case of a non-tilted smectic B phase : indeed, experimentally [5] the X-ray scattering patterns of smectic B, tilted or not, show diffuse spots localized in the same place, the only effect of tilting being to reinforce the intensity of some of them.

In a reciprocal point $\mathbf{Q}$ the $\mathrm{X}$-ray diffuse scattering intensity is given by :

$$
\langle I(\mathbf{Q})\rangle=N\left\{\left\langle|F|^{2}\right\rangle-|\langle F\rangle|^{2}\right\}+N I_{\mathrm{e}} \sum_{\mathbf{R}_{1 p} \neq 0} \sum_{s_{1}} \sum_{s_{p}} F_{1}\left(s_{1}\right) F_{p}^{*}\left(s_{p}\right) C\left(s_{1}, s_{p}\right) \mathrm{e}^{-i \mathbf{Q} \cdot \mathbf{R}_{1 p}} .
$$

- The first term represents the scattering due to complete disorder (without correlations) of the molecules.

- The second term, $\chi(\mathbf{Q})$, expresses the correlation effect and is written by means of the correlation functions $C\left(s_{1}, s_{p}\right)=P\left(s_{1}, s_{p}\right)-P\left(s_{1}\right) P\left(s_{p}\right) \cdot F_{p}\left(s_{p}\right)$ is the structure factor in $\mathbf{Q}$ of the $p$ th molecule in the $s_{p}$ state. By using $P\left(s_{1}, \ldots, s_{\mathrm{N}}\right)$, the normalized probability for a particular set of molecular configurations in the crystal, $\chi(\mathbf{Q})$ can be rewritten :

$$
\chi(\mathbf{Q})=-N I_{\mathrm{e}}|\langle F\rangle|^{2} \sum_{\mathbf{R}_{1 p} \neq 0}^{\mathrm{N}} \mathrm{e}^{-i \mathbf{Q} \cdot \mathbf{R}_{1 p}}+N I_{\mathrm{e}} \sum_{\{s\}} P\left(s_{1}, \ldots, s_{N}\right)\left\{\sum_{\mathbf{R}_{1 p} \neq 0}^{\mathrm{N}} F_{1}\left(s_{1}\right) F_{p}^{*}\left(s_{p}\right) \mathrm{e}^{-i \mathbf{Q} \cdot \mathbf{R}_{1_{p}}}\right\} .
$$

Our aim is now to write $P\left(s_{1}, \ldots, s_{N}\right)$ in a form well suited to our problem and which allows to develop $\chi(\mathbf{Q})$ in series :

- we describe the interactions between phenyl rings by use of the following compatibility function :

$$
A\left(s_{i}, s_{j}\right)=\mathrm{e}^{-\beta \omega} \text { if }
$$


i.e., we suppose, a priori, that the energy difference between $(\mathrm{C} 1)$ and $(\mathrm{C} 2)$ is weak with regard to the energy of $(\mathrm{I})$.

On the analogy of the all or nothing problems [6], we write $A\left(s_{i}, s_{i}\right)$ in the following form :

$$
A\left(s_{i}, s_{j}\right)=\frac{x^{2}-\lambda c_{i j}\left(s_{i}\right) c_{j i}\left(s_{j}\right)}{\varphi\left(s_{i}, s_{j}\right)}
$$

the definition of the $c_{i j}\left(s_{i}\right)$ is :

$$
\left\{\begin{aligned}
c_{i j}\left(s_{i}\right) & =+x \text { if the } i \text { th stick is along }\langle i j\rangle \\
& =-y \text { if not }
\end{aligned}\right.
$$

$\varphi\left(s_{i}, s_{j}\right)$ are normalization factors which make the equations (3), (5) and (6) compatible. $\lambda$ characterizes the relaxation of steric hindrance and is directly related to $\omega$ [to be submitted] : the strict steric effect corresponds to $\omega=\infty$ and $\lambda=1$ :

- the partition function $Z_{N}$ is :

$$
Z_{N}=\sum_{\{s\}} \prod_{\langle i j\rangle}^{\prime} A\left(s_{i}, s_{j}\right)=\frac{\left(x^{2}\right)^{3 N} 3^{N}}{\left(x^{2}+\lambda x y\right)^{2 N}\left(x^{2}-\lambda y^{2}\right)^{N}} \sum_{\{s\}}\left(\frac{1}{3}\right)^{N} \prod_{\langle i j\rangle}^{\prime}\left[1-\frac{\lambda c_{i j}\left(s_{i}\right) c_{j i}\left(s_{j}\right)}{x^{2}}\right] .
$$

In this form, $Z_{N}$ can be developped as a graphical series expansion $[6,10]$. If we impose the condition

$$
\sum_{s_{\imath}=1}^{3} c_{i j}\left(s_{i}\right)=0 \quad(x=2, y=1)
$$

then only the closed graphs must be counted, the series converges rapidly and the first factor in (6), which is the 0th order term, is the predominant one and recovers the Bethe approximation;

- the expression of $P\left(s_{1}, \ldots, s_{N}\right)=\prod_{\langle i j\rangle}^{\prime} A\left(s_{i}, s_{j}\right) / Z_{N}$, corresponding to (6), enables us to expand directly $\chi(\mathbf{Q})$ in series on the successive powers of $\lambda$; each order of the expansion can be represented as a graph drawn on the crystal lattice by associating each product $c_{i j}\left(s_{i}\right) c_{j i}\left(s_{j}\right)$ into bijective correspondence with one $\langle i j\rangle$ edge. So :

$$
\begin{aligned}
\chi(\mathbf{Q})= & -N I_{\mathrm{e}}|\langle F\rangle|^{2} \sum_{\mathbf{R}_{1 p} \neq 0}^{N} \mathrm{e}^{-i \mathbf{Q} \cdot \mathbf{R}_{1 p}}+N I_{\mathrm{e}}\left(\frac{Z_{0}}{Z}\right)^{N} \sum_{\{s\}}\left(\frac{1}{3}\right)^{N}\left\{\left[\sum_{\mathbf{R}_{1 p} \neq 0}^{N} F_{1}\left(s_{1}\right) F_{p}^{*}\left(s_{p}\right) \mathrm{e}^{-i \mathbf{Q} \cdot \mathbf{R}_{1 p}}\right]\right. \\
& -\frac{\lambda}{x^{2}} \sum_{\text {ed }} c_{i j}\left(s_{i}\right) c_{j i}\left(s_{j}\right)\left[\sum_{\mathbf{R}_{1 p} \neq 0}^{N} F_{1}\left(s_{1}\right) F_{p}^{*}\left(s_{p}\right) \mathrm{e}^{-i \mathbf{Q} \cdot \mathbf{R}_{1 p}}\right] \\
& \left.+\left(\frac{\lambda}{x^{2}}\right)^{2} \sum_{\text {ed }} \sum_{\text {ed }} c_{i j}\left(s_{i}\right) c_{j i}\left(s_{j}\right) c_{p m}\left(s_{p}\right) c_{m p}\left(s_{m}\right)\left[\sum_{\mathbf{R}_{1 p} \neq 0}^{N} F_{1}\left(s_{1}\right) F_{p}^{*}\left(s_{p}\right) \mathrm{e}^{-i \mathbf{Q} \cdot \mathbf{R}_{1 p}}\right]+\cdots\right\} .
\end{aligned}
$$

In spite of the presence of the molecular structure factors, the condition (7) allows us to limit the number of contributing graphs : apart from the closed graphs, only the connected graphs capable of joining site (1) to any site $(p)$ without immediate reversals contribute to $\chi(\mathbf{Q})$. The evaluation of their weight implies knowing the following relations :

$$
\begin{aligned}
-\sum_{s_{i}=1}^{3} c_{i j}\left(s_{i}\right) c_{i k}\left(s_{i}\right) & =x^{2}+2 y^{2} \quad \text { if } i, j, k \text { are aligned } \\
& =y^{2}-2 x y \quad \text { if not } \\
\text { - } \sum_{s_{i}=1}^{3} c_{i j}\left(s_{i}\right) F\left(s_{k}\right) & =\left[(x+y) F_{j}-y F_{\mathrm{T}}\right] \delta_{i k} \forall i, j, k ; \quad F_{\mathbf{T}}=F_{1}+F_{2}+F_{3} \\
& \text { etc... }
\end{aligned}
$$

For the 6 orientations model, the evaluation of $\chi(\mathbf{Q})$ can be made in the same way.

For a given $\mathbf{Q}$ vector, an algorithm is written in order 1) to research all the possible paths starting at the origin and 2) to evaluate the corresponding weights.

3. Results and discussion. - The diffuse scattering has been calculated in a quarter of the smectic plane ( $h k o)^{*}$ without taking in account the thermal scattering.
The result is the 6 orientations model, with strict or relaxed steric hindrance, leads to a theoretical X-ray scattering pattern (Fig. 4) in complete discordance with the experimental one [5]. The correlations 


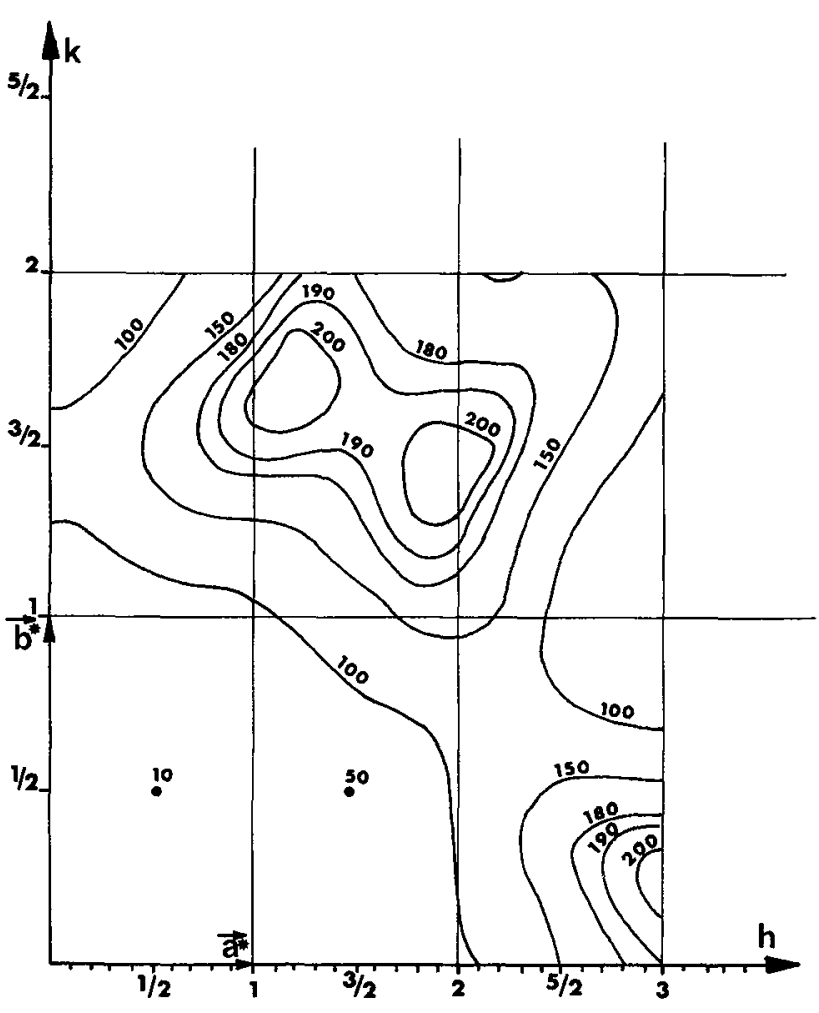

FIG. 4. - Six orientations model : theoretical isodiffusion pattern in the $(h k o)^{*}$ plane. There are no maxima in $(210),(1 / 2,3 / 2,0)$, $(5 / 2,1 / 2,0)$.

are not strong enough to produce focused spots; the influence of the molecular structure factor prevails on the correlation one.

In the 3 orientations model :

- when $\lambda=1$, the successive orders of $\chi(\mathbf{Q})$ are maximum simultaneously for $\mathbf{Q}$ vectors corresponding exactly to the experimental spots $(210),(1 / 2,3 / 2,0)$ and $(5 / 2,1 / 2,0)$; but in each of the latter the series does not converge, this shows that the model then involves correlations of the same type, but of a longer range than the experimental ones;

- when $\lambda<0.5$ (i.e. $\omega<1.25 k T$ ), in each $\mathbf{Q}$

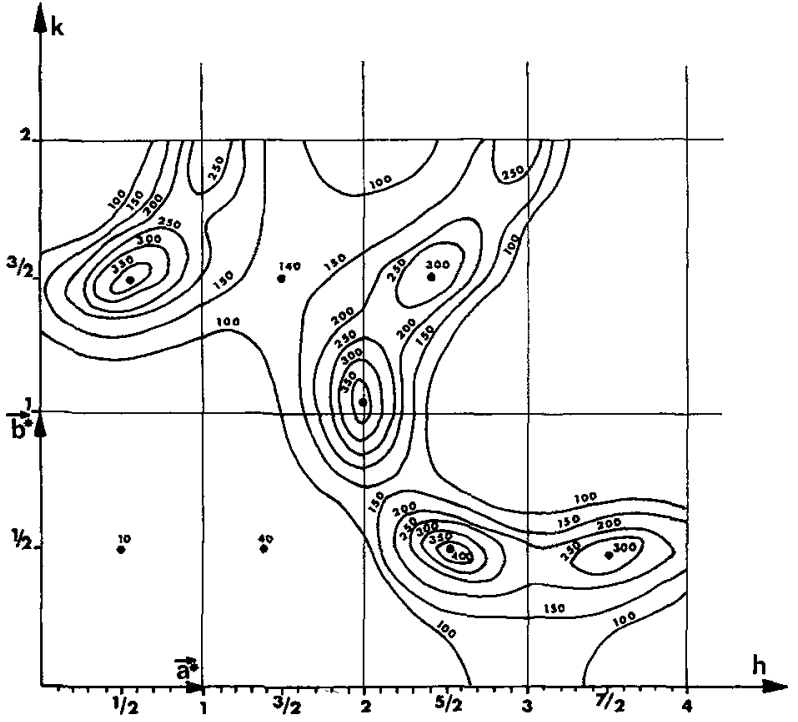

FiG. 5. - Three orientations model : theoretical isodiffusion pattern in the $h k o)^{*}$ plane.

vector the series converges very rapidly, but the theoretical diffuse spots do not coincide exactly with the experimental ones as in the 6 orientations model;

- when $\lambda=0.6(\omega=1.6 k T)$ the convergence of the $\chi(\mathbf{Q})$ expansion is good enough so that the summation of the series, limited to the 6th order, leads to theoretical diffuse spots which superimpose (localization and size) the experimental ones exactly (Fig. 5).

So, in conclusion, it is clear that an assembly of gauche molecules cannot lead to the observed X-ray scattering; on the contrary, an assembly of trans molecules can produce X-ray scattering pattern identical to the experimental one providing that steric hindrance is relaxed. This relaxation is certainly due essentially to the thermal vibrations of the molecules. But we may wonder whether that relaxation does not point out the existence of one percentage of gauche molecules which is quite likely. We have in mind the particular study of the influence of steric hindrance on the isomere ratio.

\section{References}

[1] Deloche, B., Charvolin, J., Liebert, L. and Strzelecki, L., J. Physique Colloq. 36 (1975) C1-21.

[2] Dianoux, A. J., Hervet, H. and Volino, F., J. Physique 38 (1977) 809.

[3] Levelut, A. M., Doucet, J. and Lambert, M., J, Physique 35 (1974) 773.

[4] Doucet, J., Levelut, A. M. and Lambert, M., Phys. Rev. Lett. 32 (1974) 301.
[5] Levelut, A. M., J. Physique Colloq. 37 (1976) C3-411.

[6] Descamps, M. and Coulon, G., Solid Stat. Commun. 20 (1976) 379.

[7] Charvolin, J. and Deloche, B., J. Physique Colloq. 37 (1976) C3-69.

[8] Doucet, J., Thèse de Doctorat d'Etat, Paris (1978).

[9] Descamps, M. and Coulon, G., Chem. Phys. 25 (1977) 117.

[10] Descamps, M., Chem. Phys. 10 (1975) 199. 